\title{
Study of changes in the strength of the connection between grey cattle cows and their offspring after weaning
}

\author{
Ádám Lenner ${ }^{1,2}$ - Péter Ragán ${ }^{3}$ - István Komlósi ${ }^{1}$ \\ ${ }^{1}$ University of Debrecen, Faculty of Agricultural and Food Sciences and Environmental Management, Department of Animal Husbandry, \\ Debrecen \\ ${ }^{2}$ University of Debrecen, Doctoral School of Animal Science \\ ${ }^{3}$ National Agricultural Research and Innovation Center Institute of Agricultural Engineering \\ lenner500tt@gmail.com
}

\begin{abstract}
SUMMARY
It is important to minimize stress for cattle because of animal welfare and profitability. This study aims to reveal how long after abrupt weaning the cow and her offspring show a need to rebuild the connection if physical barriers are removed and distances disappear. The research was carried out on Szamárhát Farm owned by the Tiszatáj Foundation, Hungary. In the autumn of 2019, thirty-one calves were weaned, randomly selected from 81 grey cattle cows' offspring. The oldest calf was 10 months old, while the youngest one was 6 months old on the day of weaning. They were divided into three groups and reunited with the cows during the first, third, and fifth weeks after weaning. Each reunion happened in the early afternoon and the cow and her offspring spent 24 hours together again. The formation and the strength of the connection were recorded for an hour three times during this period, first in the afternoon, then in the morning, and the next afternoon. It can be seen that both parties showed the need to form the connection during the first week after weaning because the bond made between them was obvious in a short time. The connections proved to be strong. However, neither the cows nor their offsprings showed any intention to form strong connections in the third and fifth weeks. In the majority of the cases, no connection was formed.
\end{abstract}

Keywords: behavior; attachment; Hungarian grey cattle; offspring care; animal welfare; stress; dam; weaning

\section{INTRODUCTION}

Cattle is a monophyletic (Horn, 1976; Nagy, 1996), its ancestor is the aurochs (Bos primigenius). It is one of the first domesticated species (Holló et al., 2016). It is easier to domesticate the individuals of those species whose hierarchical social life enables them to live together with humans and to accept humans as the dominant species (in this relationship) (Jensen, 2002; Goodenough et al., 2010). An important aspect to be mentioned is the loose natural connections between the individuals, the harem system. It is common among animals to live in groups. It makes it easier to detect predators, to find a mate and it also facilitates parental care (Miklósi et al., 2017).

Behavior cannot be examined isolated from other factors since the behavior of the animal is the combination of several effects. Environmental parameters have a significant impact on the life and reproduction of the animal. Behaviour is a response to the environment, which leads to a change in body position or movement (Csányi, 2002). This is a relatively fast change taking place in a short time. It can be measured and checked if repeated several times. It is more important to take into account the ,why is it doing it?" activity rather than ,what is it doing?" thus it is possible to predict the future behavior of the animal, which will make the days of the animal farmers easier (Széky, 1979). Behavior can be described by its form as well as by its function (Drummond, 1981).

There is a growing demand for the theoretical and practical knowledge of applied ethology. Animal wellbeing is an important pillar of husbandry, including cattle rearing. Animal welfare aims to make it possible for the individual to avoid negative experiences and to create such an environment that is similar to its natural habitat and in which the animal is exposed to positive experiences (Yeates et al., 2008). Efforts should be made to choose such rearing conditions that are not markedly different from the natural environment as significant differences may trigger adverse behavioral reactions, which may harm physiological processes, thereby on production.

Cattle communication is multi-layered. Being prey animals, they communicate their will primarily by using body language and vocalization very rarely happens. Vocalization occurs mainly in the relationship of the calf and the cow (Padilla de la Torre et al., 2015), but examples of vocalization may also be observed in the case of rivaling bulls. It may also be used to express other negative or positive experiences and this data can be used in precision animal husbandry (Banhazi et al., 2009; Meen, 2015; Green et al., 2019). Tail movement can be a form of communication of the calves during sucking or it is an indicator of the restlessness of a cow on heat (Jensen, 2002), regardless of the type of farming and breed. The process of calving is independent of the housing system but it does depend on the breed. The way calves are reared is determined to a large extent by humans. Calving is an easy process for some breeds while it is difficult for others who need assistance during the process.

We can talk about mainly beef cattle from a calfrearing point of view. The cow can be considered to have good calf-rearing skills if a calf gets sufficient milk with regular suckling and this ensures steady growth of the calf. (Holló et al., 2016). Besides, she protects her calf from other individuals and does not nurse other calves. This characteristic can usually be quantified with the weaning weight of the calf weighed 
on day 205 (Holló et al., 2016). The so-called prolactin hormone, which is essential in lactation, is produced in the frontal lobe of the pituitary gland (Holló et al., 2016; Sairenji et al., 2017). This hormone has been detected in other species, too, and it is correlated with the intensity of maternal instincts (Rudas et al., 1995; Kohl et al., 2016; Brown et al., 2017).

A cow giving birth in the pasture will hide its calf until it can follow the herd and in the meantime, she searches for the calf and suckles it several times a day. The cow has no difficulty in finding her calf even if the pasture looks like a monotonous landscape to the human observer or the area lacks landmarks. There are other more developed species such as chimpanzees which are characterized by the thorough knowledge of their environment (Csányi, 2002).

The ontogeny of the calves is highly dependent on technology. Calves are weaned from the cows as soon as possible in the case of those breeds where bottle feeding is used, while the calf can stay with the cow for months in the case of suckling calves. If weaning happens in the first 24 hours, it puts less stress on the calf because of the weakness of the bond (Le Neindre, 1993). However, calves reared without cows may display various kinds of abnormal behavior. One example of this is the frequent mounting behavior in adult age (Jensen, 2002).

It is natural for mammals to have a long-term social relationship between the female and her offspring, which is followed by a slow weaning process. When it comes to productive livestock, weaning of the offspring happens earlier and abruptly because of farming. This may increase the offspring yield of the breeding stock but there will be other challenges to face (Newberry et al., 2008). Livestock show clear reactions during weaning. Weaning increases the frequency of social interactions among the young thus strengthening their social bonds (Veissier and le Neindre, 1989). It is not only weaning that causes stress for the offspring but also the change in its diet, the new environment, or in some cases meeting new companions or hierarchical fighting, too (Weary et al., 2008). Several studies have been conducted to measure post-weaning stress. It can be clearly stated that sudden separation causes physiological stress both in cows and their offspring (O'Loughlin et al., 2014). It causes much greater stress than when the calf is weaned from the milk in a twostage weaning process by separating the common area with a fence or by putting a nose flap on a calf (Haley, 2006; Campistol, 2013). We can observe less vocalization, less walking, and more lying in comparison with offspring weaned by abrupt separation (Haley, 2006). This way other social bonds are maintained for some time and we can start to dry up the cow while the offspring will not lose too much weight. These are important aspects for the farmer since he can keep the annual offspring yield of his breeding stock and the offspring can be sold without weight loss days or weeks after weaning (Price et al., 2003). Another study did not show a significant difference in the weight change of abruptly weaned, calves, calves with a nose flap, and those separated with a fence. Their weight was measured regularly. Both separation with a fence and abrupt weaning were stressful for the subjects, while calves provided with a nose flap showed the lowest level of anxiety, which was also reflected in the positive weight change (Enríquez et al., 2010). Others used a blood test for the physiological measurement of stress. High adrenalin and noradrenalin levels can be detected from the blood of the subjects on the day of weaning and even the day after that (Lefcourt et al., 1995; Haley et al., 2005). It was followed by placing the cows and the offspring in adjacent pens and, as a result, the level of the two above-mentioned catecholamine hormones showed a significant decrease (Lefcourt et al., 1995). It does make a difference if the cow has calved for the first time or abrupt weaning is used after the umpteenth calving. While the former show a smaller change in her behavior, the cow having calved several times before displays a bigger behavioral change. The weaning day is also important since weaning of dairy calves in the first few hours or days will cause less stress than weaning of beef calves when they are 6-8 months old (Ungerfeld et al., 2011).

The reasons mentioned above prove that a strong connection is formed between the cow and her offspring. The present study aimed to describe by the categorical measurement of behavioral features how the detachment of the calf from the cow changes with time. One of the questions is how long they need each other's presence thus after how many days the calves show no weight gain, which is triggered by abrupt weaning. Weaning is stressful for both parties. Farmers can only rely on the signs of verbal and nonverbal communication between the cattle. It is important to understand the signs sent towards us by the cattle. In the first few days, the signs of stress are oral vocalization, exciting walking, and decreasing feed intake. There is no sign of any intention to form connections after the disappearance of vocalization and excitement. To measure this, offspring were reunited with the cows after being randomly selected in the first round, while in the second and the third rounds they were selected by sampling without replacement during the first third, and fifth weeks after weaning. The formation of the connection was recorded as well as the strength of the connection. There was an apparent decrease both in the number and the strength of the connections formed during the weeks.

\section{MATERIALS AND METHODS}

\section{Categorization of the strength or relationship}

The research took place on Szamárhát Farm owned by the Tiszatáj Foundation, Hungary. The experiment started on $21^{\text {st }}$ October 2019 when thirty-one calves were weaned, randomly selected from 81 grey cattle cows'offspring. The oldest calf was 10 , while the youngest one was 6 months old on the day of the weaning. The behavioral categories were created based on our observations and the experience of specialist literature was also taken into account. Different levels of the formation and strength of a connection between the cow and her offspring can be observed (Stehulová 
et al., 2013). Number zero is the indicator of the formation of no connection at the reunion after weaning. Number 1 was assigned to instances when the only vocalization could be heard, in these cases, oral vocalization was observed due to the considerable distance. The subjects were usually closer to each other when nasal vocalization took place or it could be heard during smelling. Smelling was usually followed by the cow licking her calf and the calf was allowed to suckle if the maternal instinct was strong enough. (Figure 1).

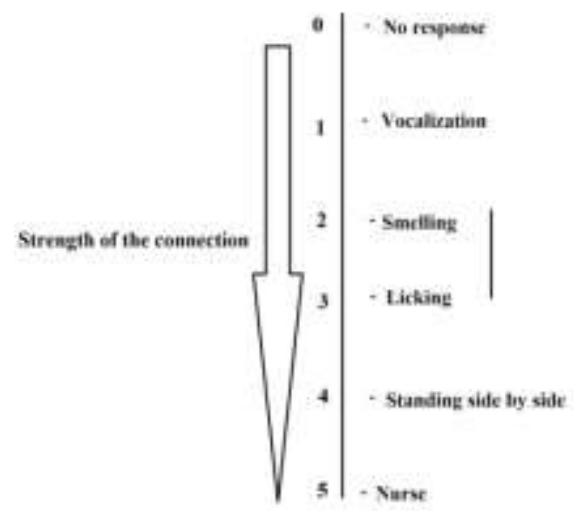

\section{Data collection}

Observations were made on three different days during the first, third, and fifth weeks after weaning. The reunion of 11 offspring took place on the first occasion and it was followed by the reunion of 10 and another 10 later. Eleven individuals were selected first with random sampling, while the second and the third time the individuals were chosen using sampling without replacement. It was closely monitored that no individual would be chosen twice or three times. On all three occasions the formation of the connection was observed for an hour at three different times: in the first hour after the reunion, the next morning, and the next afternoon. The cows and the offspring had 24 hours to form some kind of relationship with each other. During the research, if levels 1,2 , and 3 were not recorded in the first hour, but as the cow and its offspring were standing side by side the following morning (level 4) and it did not change until the end of the observation, the previous levels must have been present at some point. Suckling did not occur in a lot of instances (level 5) not even in those cases when the cow was following her offspring and the calf tried to suckle.

\section{Statistical analysis}

The statistical analysis was carried out in $\mathrm{R}$ ( R Core Team, 2020) and Rstudio (RStudio Team, 2020) software using the packet agricolae (de Mendiburu, 2020). A repeated measures ANOVA model was used for analysing cow calf connection and the LSD post hoc test was used to compare means (Huzsvai and Balogh, 2015). The repeated measurement model example script in R:

model <- aov((strength_of_connection*observation_date+Error(calf_ear_number/observation_date), data $=$ database $)$

summary(model)

The +Error defines the error of the model, which includes the three different times a measurable relationship was established between a cow and its calf, the unique identifier of the calves tested ( 31 individuals in total), ie the number of ears and the date of observation, a data $=$ indicates the source database. The summary command displays the results of the model analysis of variance.
The mean comparison of the quantified relationship strengths was performed with the LSD test, in which the smallest significant difference was determined.

In the $\mathrm{R}$ statistical environment the degrees of freedom (df) and mean squared error (MSE) needs to be defined to each post hoc test, , which was done with the following code (Huzsvai and Balogh, 2015):

$\mathrm{df}=\mathrm{df}$.residual(model\$"group1:error_of_significant_effect")

mse $=$ deviance (model\$" group 1 :error_of_significant_effect")/df

LSD<- with(datasbase, LSD.test(strength_of_connection,significant_effect_from_the_model, df, mse, console = T)) 


\section{RESULTS}

The groups of cows and adolescents were both involved in almost continuous oral vocalization, exciting walking and they hard lay down during day 1 and day 2 after weaning. Vocalization ceased by day three after weaning. The cows were lying still in the midday paddock (pen for the summertime), ruminating, just like the adolescents in the stables. Two days after weaning 11 randomly selected adolescents were reunited with the cows.

The eleven adolescents were sent back to the 173 cows at 2 p.m. Ten out of the eleven had been raising their own calf, while cow number 1361 was nursing offspring number 06000 . Cow number 1775 was its biological cow, which did not show any reaction to her own offspring. The time of observation was recording time 1 (Figure 2). A strong connection was formed between $72 \%$ of the pairs in the first hour, shortly after the reunion. The nurse cow also formed a strong connection with her reared offspring during the first minutes (recording times 1-10, Figure 2).

The second observation hour was in the early morning of the following day. The pairs observed the previous day did not change, they were loyal/ devoted to each other. The strength of the connection between the members of two new pairs was recorded in that given hour (recording time 11, Figure 2). The strength of connection proved to be strong.

The third, which was the last hour of observation, preceded the re-weaning. The strength of the connection between members of the last pair was recorded during this period and it also proved to be strong (recording time 12, Figure 2).

The time of recording has a significant impact on the strength of the connection. Significant difference: 1.0468 Significance level: $5 \%$. Recording time is those observation dates. There can be more in an hour.

Figure 2. The dynamics of the strength of connection between the cow and the calf during the first week after weaning

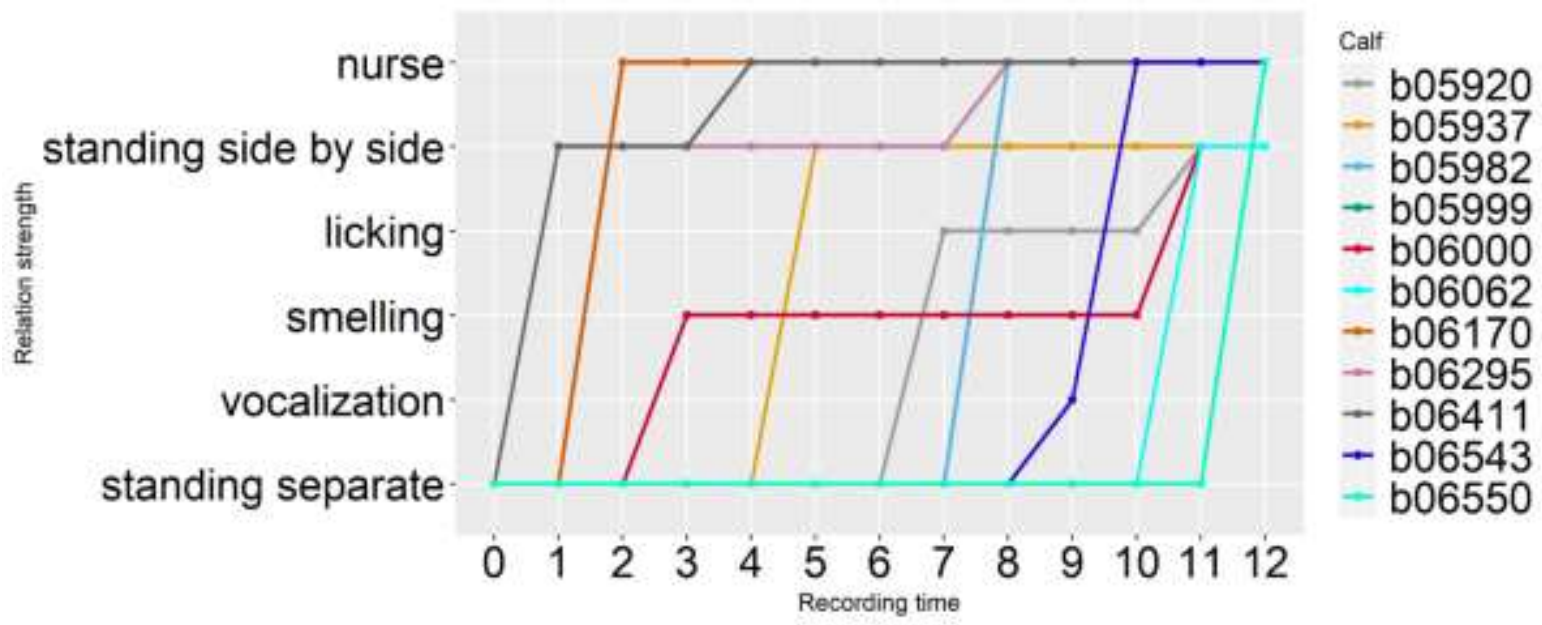

10 calves were reunited with the cows three weeks after weaning. The calves were selected using sampling without replacement. Six cows produced oral vocalization, there were a few instances of smell, some calves vocalized, but by and large, the group was calm. The number of cows, the method of reunion, and the place did not change. The calves were not allowed to enter at 2 p.m. because of stock handling and bedding removal. A few vocalizations could be heard even minutes later but the calves were standing separately and the cows were feeding undisturbed. Cow number 1510 made several nasal vocalizations while her eyes were fixed on the calves. She had met her calf during the first round and she had formed a strong connection with it again. Two nurse cows and their offspring out of the ten pairs were given a new opportunity to form a connection.

Ten percent, which is one connection, of the possible connections was formed during the first hour of the observation and it was made between cow number 1900 and her offspring number 0675 (recording time 1, Figure 3). The strength of connection at its highest level could be observed. Although the cow let her calf suckle, she had no milk. The cow was caught the following day, she was fixed in a head bail/ neck clamp and milked by hand. She did not give any milk. The time of observation is recording time 1.

The other calves were walking around, listening, drinking, and eating hay. They did not form connections with the cows, the cows showed no intention to form connections, either.

Data recording lasted for an hour early in the morning on the day after the observation. The cows and the calves were lying together. The primary reason for this was the fact that there were only island-like dry places to lie down on the bedding which was wet because of the rain. These were remains of the hay bales from the previous day. The pair from the previous day stayed together. The other calves were alone, they did not seem to be connected. Number 0616 was standing side by side with cow number 1690 (recording time 2, 
Figure 3), the cow was following its calf. The cow gave out some nasal vocalization. The calf tried to suck, but the cow did not allow it to do so. One of the cows whose offspring was also present smelled several offspring of other cows and licked one of the offspring. Cow's number 1510, 1907, and 1361 gave out continuous nasal vocalization, too. They had met their calves in the first round.

The formation of two relatively strong connections was observed during the last hour of the observation.
Standing side by side and following while moving could be observed in the case of both pairs (recording time 3, Figure 3). The former pairs retained their strength of the connection. Number 1780 gave out nasal vocalization, her calf had returned in the first round. The recording time has a significant effect on the strength of the connection Significant difference: 1.161698 Significance level: 5\%. Recording time is those observation dates. There can be more in an hour.

Figure 3. The dynamics of the strength of connection between the cow and the calf during the third week after weaning

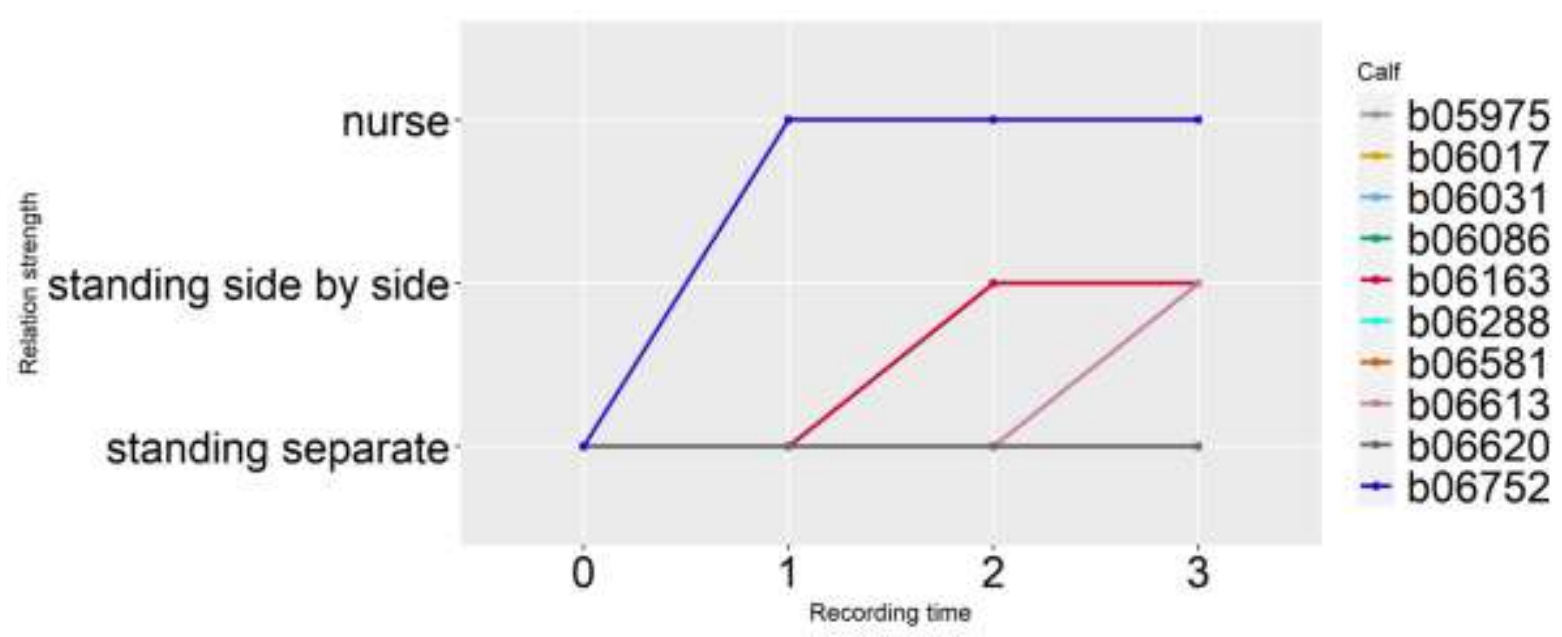

Another 10 calves were reunited with the cows five weeks after weaning. The calves were chosen by sampling without replacement, which means we made sure that the individuals which had been chosen in the previous two rounds (22) would not be selected again. The cows vocalized in groups when the calves were allowed to return. There were such cows among these whose calves had been reunited with them in the previous rounds but some of the vocalizing cows had not even given birth to a calf in the year of our study. All ten cows were allowed to form a connection with their offspring.

One of the cows gave out oral vocalization in the first hour of the reunion, but her offspring had died months before. It was not recorded whether she had suckled the calf of another dam during the remaining time. Another cow smelled one of the alien offspring, she also vocalized although she had not met her offspring since weaning. Several cows vocalized and sniffed alien offspring. All of these cows had met their offspring in the previous round. One of the offspring tried to suckle alien cows but they did not let it suckle. Vocalization ceased in the eighth minute after the reunion. One of the cows gave out nasal vocalization shortly after this, which was followed by a nasal response given out by her offspring. This kind of vocalization is a sign of a shorter distance. The two individuals observed were looking at each other, but they did not approach each other (recording time 1, Figure 4).

There were no signs of a connection between cows and calves in the second hour of checking on the day after the observation. All 10 cows were observed. They were standing separate from the offspring together with the other cows. They did not vocalize, and their body language did not indicate any intention to form a connection. There was also a considerable distance between the offspring and their cows.

During the third observation (recording time 2, Figure 4) all the cows (173) and the 10 adolescents were gathered around the head bail/neck clamp at weaning. Only number 1730 and number 0615 were loyal to each other and entered the corridor together at the same time, the cow vocalizing in the meantime. There was no other kind of contact. The recording time does not have a significant effect on the strength of the connection. Significant difference: 0.697969 1(Level of significance). Significance level: 5\%. Recording time is those observation dates. There can be more in an hour. 


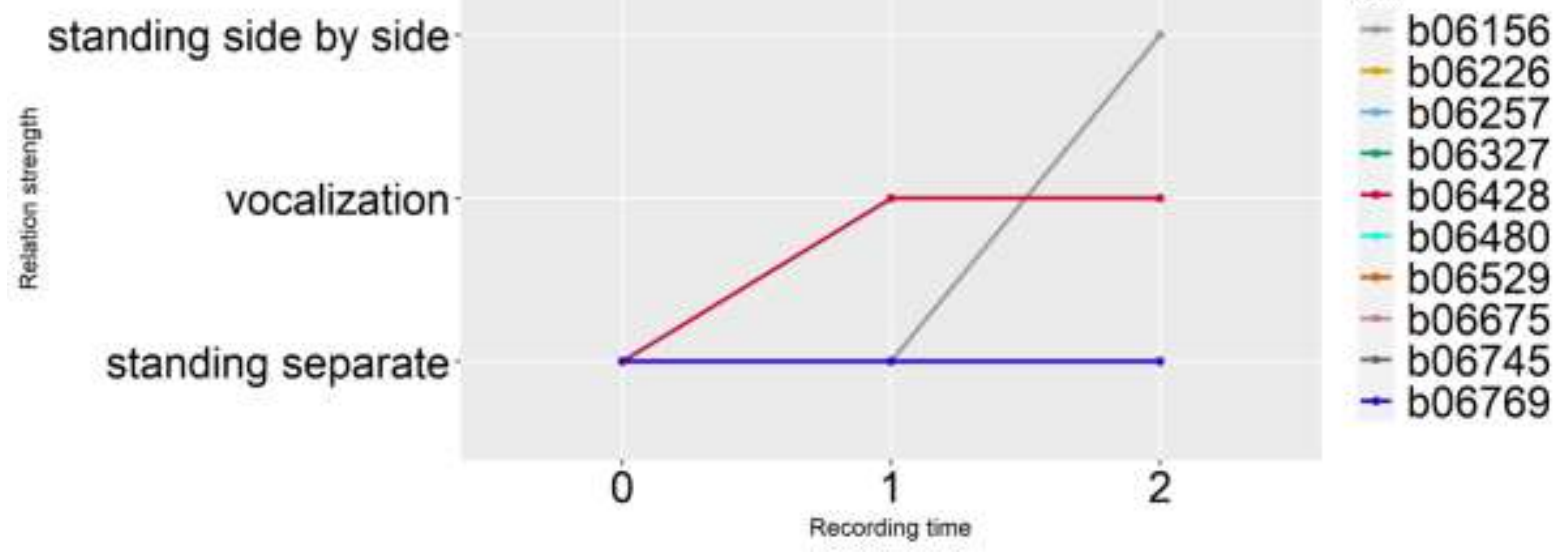

\section{DISCUSSION}

This study revealed that the number and strength of connections between cows and their offspring show a considerable decrease after weaning with time. Vocalization by both the cows and their offspring could be heard during the first two days after weaning and the animals displayed a greater need for mobility. Vocalization stopped on the third day. Eleven offspring were randomly selected on the seventh day after weaning, and they were reunited with the cows. After the reunion, the members of all the eleven pairs found each other showing some kind of sign of this with their behavior. $54 \%$ of the pairs reached the highest level of connection, suckling. 10 out of the 11 calves formed a connection with their biological cow, while one did so with a nurse cow. The first stage of being paired was vocalization in each case, which was followed by smelling, licking, and finally the intention to suckle, or suckling itself. $72 \%$ of the calves (8 individuals) showed a willingness to suckle in the first hour of the observation but the cows did not let them suckle in $37 \%$ of those cases ( 3 individuals). No other attempt to pair up could be observed. During the second observation the next morning, one calf was recorded to be suckling its cow, two pairs were standing side by side and following each other if they detected some kind of movement. It can be stated that all the cows formed a strong connection either with their offspring or with an adopted one as a result of the reunion during the first week after weaning.

10 offspring were selected by sampling without replacement on the twenty-first day after weaning. The number as well as the dynamics of the formation of the connections proved to be considerably lower than during the first observation. Only $40 \%$ of them formed some kind of a connection, and only $10 \%$ reached the formation of the strongest connection, namely suckling, even though the cow did not have any milk. The cow was caught in a neck clamp at the end of the observation and she was milked by hand to check the presence of the milk. The order in which connections were formed was the same as during the previous observation. Vocalization was followed by sniffing, licking, the willingness to suckle, and suckling. Only $10 \%$ of the pairs (1 pair) formed a connection during the first hour. Some strength of connection was displayed by an additional $30 \%$ (3 pairs) on the second day of the observation. The offspring in one pair had an apparent willingness to suckle but the cow did not allow it. However, she followed, licked, and smelled her offspring. Finally, $60 \%$ of the pairs showed no intention to form a connection of any strength. Interestingly, a few cows tried to form a connection with the offspring through vocalization, but the calves did not give any response since the vocalizing cow was not their mother. These cows had met their offspring in the first round.

Another 10 offspring that had not been involved in the observation before were selected on the $35^{\text {th }}$ day after weaning. 20\% (2 pairs) formed a very loose connection, while the other pairs showed no apparent intention to form a connection. Reciprocal oral vocalization occurred with the individuals of one pair, but no stronger connection was formed during the observation time. Another pair were involved in reciprocal nasal vocalization which was followed by sniffing, licking and then they followed each other. The offspring showed no willingness to suckle. From the two pairs mentioned before, the communication of the pair which displayed oral vocalization took place during the first hour, while the other pair connected on the next day.

So far, the studies available in specialist literature focused primarily on the biological detection and the possible reduction of the stress caused by abrupt weaning. Attempts were made to minimize the stress by using nose flaps or by erecting fences (O'Loughlin et al., 2014; Haley, 2006). Weight was measured - (Price et al., 2003; Enríquez et al., 2010) as well as hormonal changes (Lefcourt et al., 1995; Haley et al., 2005). No exact data could be found concerning how long after weaning the cow and the calf is affected by the stress 
triggered by us. Studies have primarily focused on the first few days after weaning so far (Lefcourt et al., 1995). Our present research tries to find the answer to the question of whether the stress caused by abrupt weaning can be measured in days or weeks. This is of crucial importance because it has been proved to lead to weight loss both in cows and their offspring for sale. (Price et al., 2003) Behavioral features were used as a measure, which was the same as the ones found in specialist literature (Stehulová et al., 2013), or our own experience. On farms, it is essential to collect as much data as possible about our livestock so that effective production could be achieved. The application of ethological knowledge is cost-effective even alongside regular data reporting since it enables us to make higher profits with lower expenditure.

\section{CONCLUSIONS}

It is not only the ethical duty of each farmer to comply with animal welfare criteria but it is also their interest if they want to achieve higher yield. Separation causes stress for the grey cattle cow and her offspring. Nevertheless, it is a natural process for the cow to wean her offspring giving room to her next descendant. We were looking for the answer as to how long after weaning there will be a need for rebuilding the connection if physical barriers are removed. First, the connection between the cow and her calf was categorized according to its strength. The rapid formation of a strong connection could be observed during the first week after weaning. The maternal instincts of the cows show a significant decrease in the third week after weaning and as a result, their intention to form connections was minimal. This also holds for the fifth week, during which even fewer and weaker connections were recorded. Presumably, changes in the prolactin hormone in cows play an important role in this, but this will the aim of future research. The intention to form a connection in offspring was consistent with the behavior of the cows. It is worthwhile to have this experience concerning animal welfare and apply our knowledge in practice since abrupt separation/weaning will lead to a weight loss of the offspring to be sold (Pritchard, 1990).

\section{ACKNOWLEDGEMENTS}

I would like to thank the workers of Tiszatáj Foundation for permitting me to make the observations on the Szamárhát Farm in Kesznyéten, Hungary. The publication is supported by the EFOP-3.6.3-VEKOP$16-2017-00008$ project. The project is co-financed by the European Union and the European Social Fund.

\section{REFERENCES}

Banhazi, T.M.-Black, J.L. (2009): Precision Livestock Farming: A Suite of Electronic Systems to Ensure the Application of Best Practice Management on Livestock Farms, Australian Journal of Multi-Disciplinary Engineering, 7:1, 1-14.

Brown, R.S.E.-Aoki, M.-Ladyman, S.R.-Phillipps, H.R.-Wyatt, A.-Boehm, U.-Grattan, D.R. (2017): Prolactin action in the medial preoptic area is necessary for postpartum maternal nursing behavior, https://www.pnas.org/content/114/40/10779

Campistol, C.-Kattesh, H.G.-Waller, J.C.-Rawls, E.L.-Arthington, J.D.-Engle, T.E.-Carroll, J.A.- Pighetti,G.M.-Saxton, A.M. (2013): Effects of 2-stage and total versus fence line weaning on the physiology and performance of beef steers, The Professional Animal Scientist 29 (2013):501-507.

Csányi, V. (2002): Etológia, $2^{\text {nd }}$ ed.; Nemzeti Tankönyvkiadó Bt., ISBN 963193230 3, Hungary, 83, 224.

Drummond, H. (1981): The nature and description of behavior patterns. Perspectives in Ethology, 1-33.

Enríquez, D.H.-Ungerfeld, R.-Quintans, G.-Guidoni, A.L.-Hötzel, M.J. (2010): The effects of alternative weaning methods on behavior in beef calves, Livest Sci. 128: 20-27.

Green, A.-- Clark, C.-Favaro, L.-Lomax, S.-Reby, D. (2019): Voca individuality of Holstein-Friesian cattle is maintained across putatively positive and negative farming contexts, Scientific Reports | (2019) 9:18468

Goodenough, J.-McGuire, B.-Jakob, E. (2010): Perspectives on animal behavior, 59

Haley, D.B. (2006): The behavioral response of cattle (Bos taurus) to artificial weaning in two stages, University of Saskatchewan, 5, $37,94$.
Haley, D.B.-Bailey, D.W.-Stookey, J.M. (2005): The effects of weaning beef calves in two stages on their behavior and growth rate, J Anim Sci. 83: 2205-2214.

Holló, I.-Szabó, F. (2016): Szarvasmarhatenyésztés, $1^{\text {st }}$ ed.; Mezőgazda Kiadó, Hungary, pp. 11-12, 50-51, 64, 92

Horn, A. (1976): Állattenyésztés, $3^{\text {rd }}$ ed.; Mezőgazda Kiadó, Hungary, pp. 2, 13.

Huzsvai, L.-Balogh, P. (2015): Lineáris modellek az R-ben. Seneca Books, Debrecen. 109-124.

Jensen, P. (2002): The Ethology of Domestic Animals CABI Publishing 98-106.

Kohl, J.-Autry, A.E.-Dulac, C. (2016): The neurobiology of parenting: A neural circuit perspective, Bio Essays, 39 (1), e201600159. doi: 10.1002 / bies.201600159

Lefcourt, A.M.-Elsasser, T.H. (1995): Adrenal responses of Angus x Hereford cattle to the stress of weaning, J Anim. Sci. 73: 26692676.

Le Neindre, P. (1993): Evaluating housing systems for veal calves. Journal of Animal Science 71, 1345-1354.

Mendiburu, F. (2020): Agricolae: Statistical Procedures for Agricultural Research. R package version 1.2-4. http://CRAN.Rproject.org/package $=$ agricolae

Meen, G.H.-Schellekens, M.A.-Slegers, M.H.M.-Leenders,N.L.G.Erp-van der Kooij,E.-Noldus, L.P.J.J. (2015): Sound analysis in dairy cattle vocalisation as a potential welfare monitor Computers and Electronics in Agriculture 118 (2015) 111-115.

Miklósi, Á.-Hock, F. (2017): Bevezetés a modern etológiába, VI-X fejezetek, Kézirat, ELTE TTK BI Etológia Tanszék 40.

Nagy, S. (1996): Az állattenyésztés alapjai, ${ }^{\text {nd }}$ ed.; Mezőgazda kiadó, ISBN 963923949 6, Hungary, pp. 21 
Newberry, R. C.-Swanson, J.C. (2008): Implications of breaking mother - young social bonds, Animal Behaviour Science 110, 3 23.

O’Loughlin, A.-McGee, M.-Doyle, S.-Earley, B. (2014): Biomarker responses to wearing stress in beef calves, Research in Veterinary Science 97, 459-464.

Padilla de la Torre, M.-Briefer, E.F.-Reader, T.-McElligott, A.G. (2015): Acoustic analysis of cattle (Bos taurus) mother-offspring contact calls from a source-filter theory perspective, Applied Animal Behavior Science 163 (2015) 58-68.

Price, E.O.-Harris, J.E.-Borgwardt, R.E.-Sween, M.L.-Connor, J.M. (2003): Fenceline contact of beef calves with their dams at weaning reduces the negative effect of separation on behavior and growth rate, J Anim Sci. 81, 116-121.

Pritchard, R.H.-Mendez, J.K. (1990): Effects of precondition on preand post-shipment performance of feeder calves. J. Anim. Sci. 68:28-34.

R Core Team (2020): R: A language and environment for statistical computing. R Foundation for Statistical Computing, Vienna, Austria. URL http://www.R-project.org/.

RStudio Team (2020): RStudio: Integrated Development for R RStudio, Inc., Boston, MA. URL:http://www.rstudio.com/

Rudas, P.-Frenyó, V.L. (1995): Az állatorvosi élettan alapjai, Springer Hungarica, 379.
Sairenji, T.J.-Ikezawa, J.-Kaneko, R.-Masuda, S.-Uchida, K.Takanashi, Y.-Masuda, H.-Sairenji, T.-Amano, I.-Takatsuru, Y.-Sayama, K.-Haglund, K.-Dikic, I.-Koibuchi, N.Shimokawa, N. (2017): Maternal prolactin during late pregnancy is important in generating nurturing behavior in the offspring, PNAS 13042-13047 vol. 114, no. 49.

Stehulová, I.-Spinka, M.-Sárová, R.-Máchová, L. Knez, R.-Firla, P. (2013): Maternal behavior in beef cows is individually consistent and sensitive to cow body condition, calf sex and weight, Animal Behavior Science volume 144, Issues 3-4, Pages 89-97.

Széky, P. (1979): Etológia, 1 ${ }^{\text {st }}$ ed.; Natura, ISBN 963233047 1, Hungary, pp. 12, 16.

Ungerfeld, R.-Hötzel, M.J.-Scarsi, A.-Quintans, G. (2011): Behavioral and physiological changes in early weaned multiparous and primiparous beef cows, The Animal Consortium 1270-1275.

Veissier, I.-Le Neindre, P. (1989): Weaning in calves: Its effect on social organization. Appl. Anim. Behav. Sci. 24:43-54.

Weary, D.M.-Jasper, J.-Hötzel, M.J. (2008): Understanding weaning distress, Animal Behavior Sci. 110: 24-41.

Yeates, J.W.-Main, D.C.J. (2008): Assessment of positive welfare: A review. The Veterinary Journal, 175. 293-300. 